\title{
Profitability, Trade Credit and Institutional Structure of Production
}

\author{
Michael Gofman* \\ This draft: December 2011 \\ First Draft: September 2008
}

\begin{abstract}
I use a novel database to construct structure of supply chains for 990 firms operating in five sectors of the US economy and present a methodology to measure the vertical position of each firm in the supply chain. I find that firms further up from the producers of final goods have on average larger net receivables and profits relative to their cost of production. In addition, the difference in incentive levels between a pair of firms is positively related to their relative position in the supply chain. These results are consistent with the recursive moral hazard theory of trade credit by Kim and Shin (2011). The results also suggest that to understand financial contracting between firms we need to extend the bilateral analysis to an analysis of the entire production chains.
\end{abstract}

Keywords: trade credit, institutional structure of production, buyer-seller networks, moral hazard, product quality

JEL Codes: G32, L14, L15, C21

${ }^{*}$ Wisconsin School of Business, 975 University Ave., Madison WI, 53706. Email at mgofman@bus.wisc.edu. I thank Timothy Conley, Douglas Diamond, Rinat Gofman, Milton Harris, Alon Kalay, Anil Kashyap, Roni Kisin, Mathias Kronlund, Asaf Manela, Gregor Matvos, Alan Moreira, Daniel Quint, Raghuram Rajan, Shastri Sandy, Alexi Savov, Amit Seru, Luigi Zingales for helpful comments and discussions. All remaining errors are my own. 


\section{Introduction}

Trade credit is a loan provided by a supplier to its customer. This paper empirically investigates why firms use and provide trade credit. This question is important because trade credit constitutes a large part of an average firm's balance sheet and is comparable to the size of borrowing from banks $1^{1}$ I test a theory by Kim and Shin (2011) that relates the trade credit puzzle to another seemingly unrelated question of optimal incentives mechanism in complex production chains. The transformation of natural resources into final products is not done by a single firm but by a number of firms that constitute a production chain. However, each of the firms is operating in its self-interest and a mechanism is required to align the incentives of each firm to the success of the final good. Kim and Shin (2011) propose that profits are used as a mechanism to provide incentives to the firms and that trade credit improves the feasibility of the long supply chains. The authors argue that firms may not pay for inputs immediately such that suppliers hold trade credit as a "stake" in the success of the final good. If the final good fails then all the chain is liquidated and the trade credit is not repaid.

I derive structural equations from the optimal contract solution proposed by the theoretical model. The first empirical implication relates the vertical position of a firm in the supply chain and its levels of incentives measured by profits and net receivables? The second empirical implication relates the difference in the measures of incentives and the relative position of firms in the supply chain. To estimate the structural equations I use a novel database to identify supplier-customer relationships among a large sample of firms operating in five sectors of the US economy. From these relationships I construct the structure of supply chains that produce automobiles, household durables, leisure equipment, textiles, apparel and luxury goods. Then I introduce a methodology to construct measures of vertical and relative position for firms in not perfectly vertical supply chains 3 .

\footnotetext{
${ }^{1}$ For example Rajan and Zingales (1995) document that accounts receivable constitute $17.8 \%$ of total assets and accounts payable constitute $15 \%$ of total assets on average for non-financial firms in the United States. These ratios are more than double the ratio of short-term debt to total assets (7.4\%) for the same sample.

${ }^{2}$ Net receivables equal to a difference between the amount of trade credit that a firm provides to its customers and the amount of trade credit that it receives from its suppliers.

${ }^{3}$ In the perfectly vertical supply chain described in the theoretical model firms have only one supplier and one customer.
} 
I find that firms at higher vertical position on average have more profits and net receivables divided by cost of goods sold, which are referred as normalized incentives. I also document a positive relationship between the relative position of any pair of firms in the supply chain and the difference in logs of their normalized incentives. I estimate the probability of liquidation of an average supply chain to be $4 \%$ per transaction period. According to the model the liquidation happens with a positive probability even when all firms in the supply chain exert high effort because a final good can become obsolete. To provide intuition for the estimate, I translate the probability of liquidation into annual expected rate of return on assets for an average firm. The point estimate of the expected return ranges from 16\%, when I use inventory turnover to back out the length of the transaction period, to $27 \%$ when I use trade credit turnover. The estimates are within one standard deviation from a plausable expected rate of return on assets.

The estimation results are consistent with the derived empirical implications from the theoretical model. The role of incentives in the theoretical model is to address a concern that firms in the supply chain can exert low effort levels in the production of intermediary inputs. For example, low effort can result in production of low quality goods. The model requires that the effort level is not observable by the next firm in the chain and that the effort level of all firms in the chain affects the success of the final good. The magnitude of the moral hazard problem varies with the vertical position of the firm in the supply chain. Firms that are further up in the supply chain are less sensitive to the success of the final product because their cost of shirking is going to be realized at the further period while the benefit is realized instantaneously. Therefore the optimal level of incentives is different for firms positioned differently in the chain. The reason that trade credit and profits serve as incentives is because firms risk their profits and trade credit balances when they economize on costs of production and thereby increase the probability of liquidation of the supply chain. The private benefit of shirking is bounded by the total production costs. Therefore cost of goods sold is used to normalize the incentive levels.

The advantage of the empirical analysis of trade credit applied in this paper is that it focuses on institutional structure of production chains and position of firms in this structure. This approach is justified by empirical predictions derived from the theoretical model and depends crucially on an ability to construct the production chains. 
All previous empirical tests of trade credit disregarded the position of the firm in the production process. These tests are based on the bilateral approach to explain trade credit proposed by past theories. Past theories of trade credit suggest that suppliers have an advantage over financial institutions when providing capital because of customer relationship. The relationship can generate an informational advantage about the prospects of the customer (Biais and Gollier (1997)), allow for better enforcement of repayment (Cuñat (2007)), provide an advantage in liquidating collateral (Frank and Maksimovic (1998), Santos and Longhofer (2003)), or generate customer-specific inputs that are harder to divert relative to the cash lent by banks (Burkart and Ellingsen (2004)).

However, these theories use a bilateral approach to describe an economy with only two types of firms: input supply firms with access to capital and financially constrained final good producers. This description does not explicitly address the following facts observed in the data: (i) most firms buy inputs from their suppliers and sell intermediary inputs to their customers (ii) firms simultaneously borrow from suppliers and lend to their customers, (iii) firms with better access to capital still use trade credit and firms that are more likely to be financially constrained still provide trade credit. Moreover, most of the theories would not be able to explain why firms use trade credit along with bank credit and public debt!

The moral hazard explanation for the use of trade credit in the supply chain is consistent with these empirical facts. In the theoretical model most of the firms produce intermediary inputs. I construct a vertical position measure for 990 firms. Only 187 firms belong to the consumer discretionary sector which I define as producers of final goods. Other firms are connected to these firms via many supply chains. The moral hazard explanation of trade credit allows to reconcile why firms borrow and lend simultaneously, why usage and provision of trade credit is not explained purely by access to capital and why there is a positive relationship between the amount that the firm borrows from its suppliers and the amount that it lends to its customers. However, the prediction about a positive relationship is not unique to the moral hazard explanation

\footnotetext{
${ }^{4}$ Burkart and Ellingsen (2004) present a model that reconciles a simultaneous use of bank and trade credit. However, this model is based on the assumption that inputs are harder to divert than cash. The diversion is likely to be important for small firms but is less likely to be very important for large public firms with public debt. In addition, most of the firms in the economy are not producers of final goods as assumed by their model.
} 
of trade credit. Banerjee, Dasgupta, and Kim (2004) and Fabbri and Klapper (2008) suggest that the positive relationship is related to the maturity matching between assets and liabilities conducted by firms for risk-management purposes. The results of cross-sectional analysis conducted in this paper do not provide strong support for this alternative explanation of the positive relationship. Moreover, the derived empirical predictions from the theoretical model that relate the vertical position of a firm and trade credit provide a powerful test because other explanations of trade credit don't have these predictions.

The intuition for the positive relationship between accounts receivable and accounts payable according to the Kim and Shin (2011)'s model is that firms that have higher accounts payable need to have higher accounts receivable in order to hold a positive "stake" in the supply chain. I document a strong positive and economically significant relationship between receivables and payables in the data. One standard deviation increase in payables to revenues ratio increases receivables to revenues ratio by $5.5 \%$ for an average firm. When I include revolving credit to total assets ratio as an explanatiory variable in the same regression its coefficient is only marginally statistically significant and economically insignificant. Both payables and revolving credit are short-term liabilitities and therefore the maturity matching hypothesis should suggest that they are equally likely to be used as a match for receivables which are short-term assets. However, the relationship is strong only for payables which is a support for the moral hazard explanation of this relationship. I can't fully reject the maturity matching hypothesis in this cross-sectional study because I don't observe the cost of trade credit and the cost of credit lines.

The empirical support for the moral hazard explanation of trade credit found in this paper suggests also a new look at the other empirical facts related to trade credit. The use of trade credit as an incentives device may explain why firms do not use early payment discounts as reported by Ng, Smith, and Smith (1999), why suppliers of differentiated products and of services have larger accounts receivable than suppliers of standardized goods as documented by Burkart, Ellingsen, and Giannetti (2006) why the strong positive relationship between accounts receivable and accounts payable

\footnotetext{
${ }^{5}$ They argue that the reason that suppliers of standardized goods provide less trade credit to their customers is because customers can divert these goods more easily. However, it is also more likely that suppliers need less incentives when they produce standardized goods because the quality of these goods is more observable.
} 
documented in this paper holds also in the large sample of Chinese firms as reported by Fabbri and Klapper (2008) ${ }^{6}$.

In general, my results suggest that to understand financial contracting between the firms we need to extend the bilateral analysis to an analysis of the entire production chains. More broadly, the structure of the production chains constructed in this paper can also be important to address issues such as propagation of liquidity shocks and contagion in the supply chains discussed by Kiyotaki and Moore (1997) and Boissay (2006). The paper depicts the complex structure of supplier-customer links that create a natural "space" for the analysis of the boundaries of the firm (Coase (1937)) and the institutional structure of production (Coase (1992)).

The remainder of the paper is organized as follows: In the next section I introduce the sample and the novel data source to identify supplier-customer relationships. Section 3 describes the patterns of trade credit for the firms in the sample. In Section 4 , I construct the supply chains and the measures of the vertical position. I derive the structural equations in Section 5. The estimation results appear in Section 6. Section 7 concludes.

\section{Data}

In this paper I use data available through the Capital IQ platform? 7 . One important feature of this data source is that it collects information on suppliers and customers from financial reports and public client announcements. This large scale firm-level database on supplier-customer relationships allows me to construct the supply chains between a large sample of firms and to assign a vertical position for each firm in the supply chain.

The sample selection is based on each firm's primary sector and primary industry 8 The sample only includes companies that belong to the Consumer Discretionary, Industrials, Materials, Energy and IT sectors. It excludes companies in the Financials,

\footnotetext{
${ }^{6}$ They argue that this relationship is related to the asset-liability risk management. I present their argument and attempt to test it in Section 6.3

${ }^{7}$ Capital IQ is a research platform provided by S\&P that combines information on public companies and private companies.

${ }^{8}$ The sector and industry definitions used by Capital IQ are based on the Global Industry Classification System (GICS) developed by S\&P and MSCI.
} 
Healthcare, Consumer Staples, Utilities and Telecommunication services sectors. In addition, I refine the list of industries based on the approach discussed below.

The final sample includes 2,735 firms that belong to the five sectors mentioned earlier, public or private $9^{9}$ operate in US (but are not necessarily incorporated in the US), are either independent or an operating subsidiary of another firm ${ }^{10}$, and have financial information for total assets or trade credit in any of the last three year: ${ }^{11}$. For each of the 2,735 firms, I get the information about their suppliers and customers, as well as financial information for fiscal year $2007^{12}$.

I define firms that belong to the consumer discretionary sector as 'producers of final goods'. These firms belong to the following industries: automobiles and components, household durables, leisure equipment and products, textiles, apparel and luxury goods. Firms that belong to these industries are likely to produce complex, durable goods and to be involved in larger supply chains. The moral hazard considerations described by Kim and Shin (2011) might be more pronounced in this sample and thus increase the power of the tests. I exclude firms that provide general goods or services such as transportation, media, legal and business services. These firms have customers throughout the supply chain(s) and therefore their position in the supply chain is hard to define. I exclude industrial conglomerates because not only is it difficult to measure their absolute position in the economy correctly, but including them in the sample may also assign an erroneous positions to other firms that are connected to them via supplier-customer relationships.

Next section documents some stylized facts about trade credit practices that motivate the further tests presented in this paper.

\footnotetext{
${ }^{9}$ Capital IQ provides financial data for public firms that are either large, have public debt, or were previously public.

${ }^{10}$ At the time of the data inquiry (July 2008).

${ }^{11}$ The reason for using this criterion is to decrease the sample of firms that I download because Capital IQ does not allow to perform searches that generate more than 150,000 results. Firms that have not reported trade credit balances but have other financial information could potentially bias the sample towards firms that use and provide trade credit.

${ }^{12}$ According to Capital IQ, financial reports for fiscal year end 2007 include period end dates that range between January 27, 2007 through January 6, 2008. The majority of firms (1640 out of 2438 firms that have FY2007 data) have financial statement period end dates between 28/12/2007-1/6/2008 which are based on December Fiscal Year End.
} 


\section{Patterns of Trade Credit Usage and Provision}

The descriptive statistics of usage and provision of trade credit by the firms in the sample suggest that firms with good access to capital borrow substantial amounts from their suppliers, firms with relatively poor access to capital lend to their customers and there is a strong positive relationship between the amount that a firm borrows from its suppliers and the amount it lends to its customers. These patterns of trade credit practices suggest that the difference in access to capital between the supplier and the customer can not be the only explanation of the high levels of trade credit. If a company is financially constrained we expect it to borrow from its suppliers because of their advantages as a lenders of last resort, but then it should not lend to its customers. If a company has publicly traded stocks and bonds and relatively large amounts of undrawn revolving credit then we should not expect that suppliers have any advantage in providing finance to this firm and therefore this type of firms should not borrow from their suppliers.

The summary statistics presented in Table 1 show that on average accounts receivable constitute $16.5 \%$ of total revenues and $15.5 \%$ of total asset:13. The level of accounts receivables is comparable to the level of total bank debt $(15.7 \%$ of total assets). Accounts payable for the firms in the sample constitute $10.9 \%$ of total assets which is comparable to the levels of short-term debt (10.7\% of total assets). Therefore, the levels of trade credit are significant comparing to other sources of finance. The average firm has a large exposure to its customers and an average 60 days of credit. This is a suggestive evidence that trade credit is not just a loan for a period required to deliver a good from a seller to a buyer.

The following statistics suggest that not only trade credit usage and provision levels are significant, but also that firms with comparably good access to finance use trade

\footnotetext{
${ }^{13}$ I use the most recent version of financial statements available as of July 2008. Currency conversion is done according to historical exchange rates. When computing financial ratios, I disregard observations with non-positive total revenues or total assets, observations with receivables or payables to total revenues or to total assets that are below 0 or greater than or equal to 1 . For the profitability measures, I define observations with profit margins (EBITDA, EBIT, Net Income to Total Revenues) that are greater than or equal to 1 or less than or equal to -1 as missing. I also define observations with Short-Term Debt to Total Assets ratios greater than 1 or less than 0 as missing and I use the same principal for the Revolving Credit to Total Assets ratio. I winsorize financial ratios at the $1 \%$ and $99 \%$ levels. Accounts Receivable Balances are net after allowances for bad debt.
} 
credit and firms that might be financially constrained provide trade credit. The median firm in the sample has book value of total assets of $191(\$ \mathrm{~mm})$ and 563 employees. As reported in Table 2, firms with above the median book value of total assets still use trade credit (mean ratio of accounts payable to total assets is $9 \%$ ), and firms with below median book value of total assets provide trade credit (accounts receivable to total assets ratio is $16.3 \%$ ). Firms with less than 500 employees ${ }^{14}$ provide trade credit (accounts receivable to total assets ratio is $14.4 \%$ ) and firms with above 500 employees use trade credit (mean ratio of accounts payable to total assets is $7.6 \%$ ). Therefore, if size is a measure of access to capital, firms that are less likely to be financially constrained still use trade credit and firms that are more likely to be financially constrained still provide trade credit.

Second, the sample includes both public and private firms 15 as well as firms with and without public debt. Public firms or firms with public debt still borrow from their suppliers (payables to total assets ratio is $7.8 \%$ and $8.8 \%$ respectively). Firms with above median ratio of undrawn revolving credit to total assets, borrow on average $7.7 \%$ of their total assets from their suppliers. Sufi (2008) suggests that lack of access to lines of credit can be a measure of financial constrains that firms face, therefore firms that have large ratio of undrawn revolving credit might be considered as less financially constrained.

Finally, if trade credit was used only by financially constrained firms and provided only by firms with good access to finance then we would not observe positive correlation of $25 \%$ between accounts receivable and accounts payable (normalized by total revenues) for the firms in the sample. When we normalize receivables and payables by total assets the correlation between provision and usage of trade credit is $44 \%$. The strong positive correlation suggests that firms in the sample simultaneously borrow from their suppliers and lend to their customers.

The positive correlation between accounts receivable and accounts payable is a piece

\footnotetext{
${ }^{14}$ Less than 500 employees is one of the criterions for a firm to be defines as Small-Medium Enterprise (SME) and to participate in the National Survey of Small Business Finance (NSSBF) used in empirical studies of trade credit such as Petersen and Rajan (1997) and Burkart, Ellingsen, and Giannetti (2006).

${ }^{15}$ The private firms in the sample that have financial information include large firms, firms that were previously traded and firms that have privately traded debt.

${ }^{16}$ Statistically significant at $1 \%$ level.
} 
of evidence in favor of the moral hazard explanation of trade credit proposed by Kim and Shin (2011). In their model firms that have more accounts payable need to have more accounts receivable in order to have incentives to overcome the moral hazard problem. In order to get more power in tests of the moral hazard explanation of trade credit, I derive two types of structural equation from the optimal contract solution (Section 5). The first type relates the normalized level of incentives to the absolute vertical position of each firm in the supply chain. The second type relates the difference in the levels of incentives and the relative position of each pair of firms in the supply chain. The next section describes the methodology to construct the supply chains and to build the measures of absolute and relative position.

\section{Construction of the Supply Chains}

In order to measure the position of a firm in the production process, I need to identify all supplier-customer pairs among the 2,735 firms in the sample. To create these relationships, I match firms based on the list of suppliers of each firm. When I find a match, I define a pair of firms, where the first firm is the customer and the second firm is the supplier.

The matching procedure creates 4,168 pairs of firms \{customer, supplier\} among the 2,735 firms in the sample. The number of firms that have at least one supplier or customer is 1,418 . I refer to this set of firms as the connected set.

In the initial sample there are 1,317 firms that have neither a single supplier nor customer among the other 2,734 firms. This can occur if their list of suppliers is empty or if it includes firms that have not met the selection criteria. The analysis presented in the paper focuses only on the connected set of firms.

In the connected set of 1,418 firms, the average (median) number of suppliers and customers is $2.94(1)^{17}$. The maximum number of suppliers is 95 and the maximum number of customers is 75 . There are 482 firms that have no suppliers and 364 firms that have no customers among the firms in the connected set.

\footnotetext{
${ }^{17}$ The average number of suppliers and customers is the same when I calculate the unconditional average. The average number of suppliers is 4.45 among firms that have at least one supplier and the average number of customers is 3.95 among firms that have at least one customer.
} 
Next I present the methodology to create the measures of absolute and relative position and apply it to the firms in the sample.

\subsection{Measures of Position in Supply Chain}

In a perfectly vertical supply chain, the absolute position of each firm equals to the number of links that separate it from the producer of the final good and the relative position between any two firms equals to the difference in their absolute positions. The industrial structure observed in the data includes firms with more than one supplier or customer. Therefore I need to define absolute and relative positions measures for the more complex production chains.

In order to define the absolute position of a firm I need to define a set of firms that produce a final good. All firms in this set are assigned position 0. All firms that supply goods to either of the firms in the set of firms with a position of 0 are assigned position of 1 . All firms that supply goods to any of the firms at position 1 are assigned a position of 2 and so forth. I refer to this definition of absolute position as the minimum measure of absolute position. If all firms in the sample have no more than one supplier or customer then the minimum measure of absolute position equal the position assigned to each firm according to Kim and Shin (2011) model.

Figure 1 illustrates an example of supplier-customer relationships between a subsample of 26 firms. The vertical position of each firm in the figure is calculated according to the minimum measure of absolute position. Firms that belong to the industry of producers of consumer electronics $(3,8,17,20$, and 26) are at the bottom of the figure and are assigned position 0 . The highest vertical position in this example is 3 . Firms at position 3 (firms with numbers 22, 21, and 24) supply inputs to at least one firm at position 2 but don not supply inputs to any of the firms with a position smaller than 2 directly.

One limitation of the minimum measure is that it focuses only on the producer of final goods that is related to the firm via the smallest number of supplier-customer relationships. This measure disregards the position of each firm relative to other producers of final goods. I calculate an additional measure that takes into account the position of each firm relative to other producers of final goods as well. To define this 
measure, first I calculate the shortest supply chain that connects each firm with each producer of final goods. Then I calculate the length of these supply chains by counting the number of supplier-customer links they include. The result of this analysis is a list of distances for each firm relative to all of the producers of final goods it is connected to. Finally, I obtain the median distance over all the distances and define it to be the median measure of position for the firm.

In the supply chains where firms have more than one supplier or customer, the relative position between a pair of firms is defined as the number of supplier-customer relationships across the shortest possible supply chain that connects them. In Figure 1. there are 91 pairs of firms that are connected. For example, among the set of firms number $(5,6,16,17,20)$ the relative position of 5 with 6,6 with 20,6 with 17 , and 16 with 17 is 1 , while the relative position of 5 with 20 and 5 with 17 is 2 .

Next I apply the definition of the absolute position measure to the firms in the connected set. Among 1,418 firms in this set, 190 firms belong to the consumer discretionary sector and are defined as producers of final goods. However, 425 firms in the connected set do not belong to the supply chains that include any of the 190 firms. Therefore, I need to exclude these 425 firms from the sample because it is not possible to calculate the absolute position for these firms. In addition, among the 190 firms that belong to consumer discretionary sector there are 3 firms that do not have suppliers among the firms in the connected set. Therefore, I calculate the measures of absolute position for the final set of 990 firms. The graphical representation of the minimum measure appears in Figure 2 and of the median measure in Figure 3. In these graphs the vertical position of each firm is calculated according to the minimum and median measures.

For the 990 firms in the final set, the minimum measure of position ranges from 0 to 7 , the average of the measure is 2.1 , the median of the measure is 2 , and standard deviation of the measure is 1.5 . The median measure of position ranges from 0 to 11 , the average of the measure is 4.7 , the median of the measure is 5 , and standard deviation of the measure is 2.6. The correlation between the minimum measure and the median measure is $77 \%$.

In the further empirical analysis I use the relative measure of position for 190,493 
pairs of firms ${ }^{18}$ The relative position measure for these pairs of firms ranges from 1 to 19 , the average of the measure is 5.5 , the median of the measure is 5 , and standard deviation of the measure is 2.6. The histogram of the relative position measure appears in Figure 4.

In the next section I provide an intuition for the Kim and Shin (2011) model and derive structural equations from their optimal contract solution.

\section{Derivation of the Structural Equations}

Kim and Shin (2011) model a perfectly vertical supply chain, where each firm $(i)$ in the chain supplies inputs to the next firm in the chain $(i-1)$, and the firm at the bottom $(i=0)$ of the chain produces the final good. Each firm in the chain can exert high or low effort in the production of its output. For example, we can interpret low effort as hiring a suboptimal number of employees by some firm in the supply chain relative to the first best number of employees. The suboptimal hiring decision can result in production of low quality intermediary input that affects the quality of the final product. The optimal contract needs to align the incentives of individual firms with the objectives of the entire supply chain because firm's effort is not observed by the next firm in the chain.

In their model, firms have two channels with which to align incentives and ensure that high effort is exerted by all firms in the chain. The first channel is via the firm's profitability. If firms are more profitable they will have less incentives to shirk and threaten their stream of profits. The second channel is via a firm's trade credit contracts. The authors argue that firms may not pay their suppliers immediately such that they hold a stake in the success of the final good. If the final good fails then all the chain is liquidated, the inventory has no value outside the supply chain and the trade credit is not repaid.

The assumption of the model is that each firm in the perfectly vertical supply chain requires one unit of time to produce its output. The cost of low effort is lower for firms that are further from the producer of the final good because it takes longer for their

\footnotetext{
${ }^{18}$ These pairs include 748 firms out of 990 firms because only for these firms the proxy for the incentives could be constructed.
} 
effort level to affect the probability that the final product becomes obsolete. On the other hand, the benefits of low effort are unrelated to the position of the firm in the supply chain. The combination of lower costs and similar benefits from low effort levels imply that firms at higher vertical position need to have more incentives.

I start the derivation of the empirical specifications from the solution to the optimal contract provided in equation (13) of Kim and Shin (2011):

$$
a_{i} p_{i}=a_{i+1} p_{i+1}+b_{i} w_{i}-\left(p_{i}-p_{i+1}-w_{i}\right)
$$

In Eq.(1), $a_{i} p_{i}\left(a_{i+1} p_{i+1}\right)$ is referred to an outstanding balance of accounts receivable (payable) of firm $i, p_{i}$ denotes revenues of firm $i, p_{i+1}$ is the cost of inputs paid by firm $i$ to its supplier firm $i+1$, and $w_{i}$ is the cost of production of firm $i$ (cost of goods sold excluding the cost of inputs). The interpretation of Eq.(1) is that net accounts receivable $\left(a_{i} p_{i}-a_{i+1} p_{i+1}\right)$ and profits $\left(p_{i}-p_{i+1}-w_{i}\right)$ need to be large enough to ensure that firm $i$ prefers to exert the first best effort rather than to shirk and get a one period benefit of $b w_{i}$. The definition of $b_{i}$ is given by equation (5) in their paper:

$$
b_{i}=b \frac{\pi^{H}}{\left(\pi^{L}-\pi^{H}\right)\left(1-\pi^{H}\right)^{i}}
$$

In Eq.(2), $b>0$ is the per-period private benefit (as a percent of a firm's net costs) that a firm enjoys if it exerts low effort. The private benefits parameter $b$ is assumed to be common to all firms. If all firms in the supply chain exert high effort, then the probability that the chain is liquidated is $\pi^{H}$, if any of the firms exerts low effort then the probability is $\pi^{L}>\pi^{H}$.

In the model, the output produced by firm $i$ is sold as part of the final product in $i$ periods because each firm requires one period to produce its output and there are $i$ firms down the chain (firms at positions: $i-1, \ldots, 0$ ). Under this assumption the incentive compatibility constrain of firm $i$ should include a term that accounts for the fact that the costs of shirking (increase in probability of liquidation of the chain) occur $i$ periods after the benefits of shirking $\left(b w_{i}\right)$. This difference is embedded in the $\left(1-\pi^{H}\right)^{i}$ term in Eq. (2) which is similar to the compounded discount rate with $i$ the number of periods of compounding.

However, firms might realize the benefits of shirking not exactly at the end of the production cycle. Some firms can save costs prior to producing the output, others 
might be able to realize the benefit of shirking only after the output is produced. These deviations from the assumption of the model justify an introduction of an error term $\epsilon \sim N\left(0, \sigma^{2}\right)$. The error term captures deviations in the realization of $b w_{i}$ relative to the end of the period. Under that specification, the cost of shirking is realized $i+\epsilon$ periods after the realization of the benefit of shirking. I assume a non-zero spatial correlation between adjacent firms in a supply chain because timing of realization of the benefit can be related to the type of transaction or technology employed by the two firms involved in a supplier-customer relationship 19

To derive testable empirical specifications from the optimal contract solution, I rearrange Eq.(1), and leave only the $b_{i}$ term on the right hand side while substituting it in Eq. 22):

$$
\frac{a_{i} p_{i}-a_{i+1} p_{i+1}+\left(p_{i}-p_{i+1}-w_{i}\right)}{w_{i}}=b \frac{\pi^{H}}{\left(\pi^{L}-\pi^{H}\right)\left(1-\pi^{H}\right)^{i+\epsilon}}
$$

Equation (3) relates the normalized incentives of each firm to its absolute position in the supply chain. The normalized level of incentives are composed of profits and net receivables (accounts receivable - accounts payable) divided by net cost of production.

To make the equation linear in $i$, I take logs of both sides of Eq. (3.

$\log \left(\frac{a_{i} p_{i}-a_{i+1} p_{i+1}+\left(p_{i}-p_{i+1}-w_{i}\right)}{w_{i}}\right)=\log \left(\frac{b \pi^{H}}{\pi^{L}-\pi^{H}}\right)-\log \left(1-\pi^{H}\right) i-\log \left(1-\pi^{H}\right) \epsilon$

Next I derive a structural equation that relates the relative levels of incentives and the relative position between any pair of firms. There is a number of benefits of the pair-wise specification. First, it increases the power of the tests as it uses much more information available in the structure of supplier-customer relationships. Second, the pair-wise approach overcomes the difficulties to measure the absolute position of a firm when each firm is involved in several supply chains. Third, it allows to estimate the model for any subset of firms that are connected with supplier-customer relationships and does not require to define producers of final goods.

To derive the implication for the relative position, consider two firms: firm $i$ and firm $i+j$ such that $j>0$, that belong to the perfectly vertical supply chain described in the model. The parameter $j$ defines the relative position between the two firms.

\footnotetext{
${ }^{19}$ In section 6.2 . I show that conclusions are unchanged when I cluster firms by industry.
} 
Equation(4) is an equilibrium condition that should hold for firm $i$ and for firm $i+j$. I create a difference equation where I subtract the Eq. (4) for firm $i$ from that for firm $i+j$ :

$$
\log \left(L_{i+j}\right)-\log \left(L_{i}\right)=-\log \left(1-\pi^{H}\right) j-\log \left(1-\pi^{H}\right)\left(\epsilon_{i+j}-\epsilon_{i}\right)
$$

where $L_{k}=\frac{a_{k} p_{k}-a_{k+1} p_{k+1}+\left(p_{k}-p_{k+1}-w_{k}\right)}{w_{k}}$.

The interpretation of Eq. (5) is that in the perfectly vertical supply chain the difference in the levels of normalized incentives should on average only depend on the relative position of the firms in the chain $(j)$ and the probability that the final product will become obsolete $\left(\pi^{H}\right)$.

For each of the derived specifications I construct the empirical counterpart that I estimate. In Eq.(6) I define the empirical specification based on the Eq.(4):

$$
\log \left(\frac{\operatorname{NetRec}_{j}+\operatorname{EBITDA}_{j}}{\operatorname{NetCost}_{j}}\right)=\alpha+\beta \text { Position }_{j}+\eta_{j}
$$

Similarly, based on the Eq.(5) I define the following empirical specification for all pairs of firms that belong to the same supply chain:

$$
D_{k}=\alpha+\beta \text { RelativePosition }{ }_{k}+\zeta_{k}
$$

where $D=\log \left(\frac{\operatorname{NetRec}_{i+j}+E B I T D A_{i+j}}{\text { NetCost }_{i+j}}\right)-\log \left(\frac{\operatorname{NetRec}_{i}+E B I T D A_{i}}{\text { NetCost }_{i}}\right)$.

The table below provides the mapping between the theoretical parameters and the empirical proxies used in Eq.(6) and Eq.(7). 


\begin{tabular}{lll} 
Variable & Full Name & Short Name \\
\hline \hline$a_{i} p_{i}$ & Accounts Receivable per period & Rec \\
$a_{i+1} p_{i+1}$ & Accounts Payable per period & Pay \\
$a_{i} p_{i}-a_{i+1} p_{i+1}$ & Net Accounts Receivable & NetRec \\
$w_{i}$ & Cost of Goods Sold minus Cost of Inputs & NetCost \\
$p_{i}-p_{i+1}-w_{i}$ & Revenues - Cost & EBITDA \\
$i$ & Absolute vertical position & Position \\
$j$ & Relative vertical position & RelativePosition \\
$\log \left(\frac{b \pi^{H}}{\pi^{L}-\pi^{H}}\right)$ & Constant term in Eq. (6) & $\alpha$ \\
$-\log \left(1-\pi^{H}\right)$ & The slope in Eq. 6 and Eq. (7) & $\beta$ \\
$-\log \left(1-\pi^{H}\right) \epsilon$ & The error term in Eq. (6) & $\eta$ \\
$-\log \left(1-\pi^{H}\right)\left(\epsilon_{i+j}-\epsilon_{i}\right)$ & The error term in Eq. (7) & $\zeta$ \\
\hline
\end{tabular}

I use the minimum and median measures of position as proxies for the Position and the relative position measure as a proxy for the RelativePosition.

The NetCost parameter refers to the cost of production excluding the cost of inputs. It is hard to measure what fraction of cost of goods sold (COGS) arises from the firm's activity as opposed to the inputs bought from suppliers, because this information is not available from financial reports. I use cost of goods sold (COGS) as a proxy for NetCost. Moreover, in many cases, the customer firm is unable to observe the quality of inputs used by its supplier. Therefore, when firms can choose between several suppliers, they can save costs of production by purchasing less expensive inputs with lower quality. As a result, the use of cost of goods sold (COGS) which includes the cost of inputs can be a more reasonable proxy for NetCosts. For robustness check, I use number of employees as a proxy for NetCost assuming that using a suboptimal number of employees can be one of the ways for firms to shirk 20 .

By estimating Eq.(6), we can use the estimate of beta to derive estimates of $\pi^{H}$ in the following way: $\widehat{\pi^{H}}=1-\exp (-\widehat{\beta})$. Using the delta method we can also derive the standard error of the estimate of $\pi^{H}$ which is equal to $\exp (-\widehat{\beta}) * \operatorname{se}(\widehat{\beta})$. The other two parameters $b$ and $\pi^{L}$ are included in the intercept $\alpha$ and can not be identified separately.

The spatial correlation structure of the errors in $\mathrm{Eq}(6)$ and in $\mathrm{Eq}(\sqrt{7})$ is important

\footnotetext{
${ }^{20}$ Ideally I would use cost of labor but it is unavailable in Capital IQ.
} 
for the inference. For the specification in Eq.(6), I assume that error terms of two firms are non-independent whenever these firms are adjacent in the supply chain (one firm supplies to the other firm). An alternative assumption that I use in the robustness checks is that all firms that belong to the same industry have non-independent error terms ${ }^{21}$. For the specification in Eq. (7) where the unit of observation is a pair of firms, I assume that error terms of two pairs are non-independent whenever the two pairs of firms share a common firm.

I the next section, I estimate Eq.(6) and Eq.(7) and test whether the implied estimate of $\pi^{H}$ is positive, and whether the intercept in specification Eq. (7) is indistinguishable from zero. In addition, I try to assess how reasonable the implied probability of obsolescence that I estimate.

\section{Estimation Results}

Table 3 presents the results from the estimation of Eq.66. In specifications (1) and (2), the dependent variable is the log of the sum of EBITDA and net receivables divided by the cost of goods sold or the number of employees respectively. The slope in these specifications, $\beta=-\log \left(1-\pi^{H}\right)$, is expected to be positive.

We can learn from the results of the estimation that both the minimum and median measures of position have coefficients that are positive and statistically different from zero 22 The results of the estimation suggest that among firms with positive incentive levels ${ }^{23}$, there is a positive relationship between the measures of position and the measure of normalized incentives. The result is consistent with the derived predictions.

The estimation results for the pair-wise specification Eq(7) are reported in Table 4 . The first specification uses all pairs of firms that belong to the same production chain.

\footnotetext{
${ }^{21}$ There are 22 industries defined at the six digits GIC code level.

${ }^{22}$ In unreported results I used average distance and maximum distance as alternative proxies for the vertical position of each firm in a production chain. For both proxies the slope in all six specifications is positive and statistically different from zero.

${ }^{23} \mathrm{Eq}$. (6) can not be estimated for observations with negative incentive levels because the theoretical model is developed under the assumption of stationarity. Specifically, the model assumes that given that the supply chain is not liquidated, each period is identical. This condition limits the sample to firms with positive values for the sum of EBITDA and net receivables.
} 
The second specification excludes dublications when one firm is a direct or indirect supplier to another firm in one observation and the opposite is true in another observation. It happens because there are loops in production chains composed of supplier-customer relationships. I assume that the true production chain is the one where the distance between the two firms is the shortest. In the third specification I further exclude all pairs that have loops, potentially eliminating relationships along the true production chains. The results in all three specifications show that the coefficient on the relative position measure is positive and statistically significant. The results of the estimation suggest that there is a positive relationship between the relative measure of the normalized incentives and the relative position measure ${ }^{24}$. In addition, the constant in this regression is positive but statistically indistinguishable from 0 . The pair-wise regression has more power to reject the model relative to the firm-level regression because there are thousands of observations and because of the additional empirical prediction about the intercept. In addition, while the firm-level regression imposes the same intercept for all firms, effectively assuming the same moral hazard problem for all production chains, the pair-wise regression does not require this assumption, it allows us to test whether the moral hazard problem is the same for firms that belong to the same production chain as it is suggested by the recursive moral hazard model. The statistical significance of the slope in the pair-wise regression is higher in the second specification, suggesting that accounting for the "loops" improves the fit of the model. The results in the third specification suggest that by eliminating both observations that constitute a loop and not only the one with the highest distance as in the second specification we eliminate true production chains and decrease the fit of the model. Overall, the estimation results provide a strong evidence in favor of the model.

The model suggests that both profits and net receivables play a role of incentives. It is important to understand whether trade credit in particular plays any role as an incentive device. I estimate specifications (3) and (4) in Table 3 which include only trade credit as incentives device. The coefficients on the absolute position (both the minimum measure and the median measure) for both specifications are positive and statistically significant at the $1 \%$ level. I also exclude net receivables from equation (6) and estimate it using only measures of EBITDA. The results of this estimation are reported in specifications (5) and (6) of Table 3 . The coefficients on the absolute

\footnotetext{
${ }^{24}$ In this specification the measure of normalized incentives is the log of the sum of profits and net receivables divided by COGS.
} 
position (both the minimum measure and the median measure) for both specifications are positive and statistically significant at the $1 \%$ level. The results suggest that not only is the total amount of incentives is positively related to the vertical position but also, that each one of the incentives is seperately related (positively) to the absolute position as well. This result supports the hypothesis that trade credit is used as an incentives device in the supply chains.

\subsection{Quantitative Assessment of the Model}

The structural approach allows not only to test the model qualitatively but also to assess whether the implied estimates are reasonable. First, I will argue that quantitative estimates of the pair-wise regression are more appropriate relative to the firm-level regression. Second, I will calculate the implied probability of obsolescence. Then I will present a way to translate this probability into a discount rate. Finally, I will proxy for the length of the average transaction period and will translate the implied discount rate into an annual expected rate of return on assets.

The firm-level regression captures two types of variation in the incentive levels. There is a "within" the supply chain variation that suggests that firms at higher vertical positions need to have more incentives and there is a "between" the supply chains variation that suggests that more incentives are required to make longer supply chains feasible ${ }^{25}$. The implied probability of obsolescence from the firm-level regression can be overstated because of the second type of variation in the incentive levels. For example, a firm with an absolute position of 2 can have smaller incentives than firm at position 5 either because it belongs to the same supply chain or because it belongs to the different supply chain of length 2 which is shorter and therefore requires less incentives to keep it feasible. Therefore, positive estimated $\beta$ in the firm-level regression is an evidence in favor of the mode ${ }^{26}$ but it can not be used for the quantitative assessment of the model. The pair-wise regression focuses on the "within" variation in the incentive levels because it uses pairs of firms that belong to the same supply chain. I use the estimates from the pair-wise regression to make the quantitative assessment of the model.

\footnotetext{
${ }^{25}$ For a given profitability of the final good the first best effort can be implemented only for a limited length of the supply chain. The usage of trade credit relaxes the IC constrain and allows to implement the optimal effort for a longer supply chain.

${ }^{26}$ Both "within" and "between" variations in incentives are a direct implication of the model that are not predicted by other models.
} 
Based on the estimate of $\beta$, the implied estimate of $\pi^{H}$ in the pair-wise regression is $5.45 \%\left(\pi^{H}=1-\exp (-\beta)\right) \cdot{ }^{27}$ In order to get some intuition for the value of $\pi^{H}$, we need to understand its role in the theoretical model. The present value calculation in the model multiplies the cash flow received at time $t$ by $\left(1-\pi^{H}\right)^{t}$ which is the probability that the final good is not liquidated after $t$ periods. Therefore, this parameter ensures that even when all firms in the supply chain exert high effort, their cash flow is still uncertain. We can also define a discount rate $r$ such that the cash flow received on date $t$ is multiplied by $\left(\frac{1}{1+r}\right)^{t}$ when computing its present value. There is a positive relationship between the level of $\pi^{H}$ and the level of $r$. In the model, the probability of obsolescence increases from $\pi^{H}$ to $\pi^{L}$ when one of the firms in the supply chain shirks. Therefore, the interpretation of low effort by any of the firms in the supply chain is equivalent to increasing the expected return on assets. We can use a simple formula to define the discount rate consistent with the probability of obsolescence described in the model: $r=\frac{\pi^{H}}{1-\pi^{H}}$. Using the delta method, we can derive the standard error for the discount rate estimate as $\operatorname{se}(\widehat{r})=\exp (\beta) * \operatorname{se}(\widehat{\beta})$.

The implied estimate of the expected rate of return on assets from the pair-wise regression is $5.76 \%$ (std. error $1.84 \%$ ). However, we need to know what the relevant time period is for the discount rate. The model assumes that it takes one unit of time for each firm to deliver its output to the next firm in the chain. It also takes the same unit of time for the firm to repay its current payable balance. The probability of obsolescence in the model is defined over the same period of time and consequently the discount rate refers to this period as well.

There are two potential ways to back out the average transaction period in the sample. First, we can use the information about inventory levels. In the sample, the average number of days it takes for the firm to sell its inventory is around 100 days (inventory/cost of goods sold *365). Second, we can use information on the average turnover rate of trade credit. Based on the average ratio of receivables to total revenues $(16.5 \%)$ for firms in the sample, the average number of days receivables is approximately 60 days (recievables / total revenues * 365)

\footnotetext{
${ }^{27}$ I use the estimate of beta (0.056) from the second specification in Table 4 because it adjusts for loops in the production chains.

${ }^{28}$ This estimate may be downward biased because I use receivables after allowances for bad debt.
} 
Using the estimates of the transaction period (60-100 days), the $5.76 \%$ interest rate for the transaction period implies an annual discount rate of $23-41 \% 29$. This estimate is within two-standard deviations from a reasonable number for the average expected return on assets for a large sample of firms. In addition, the model uses a number of assumptions that could potentially affect the estimated parameter. For example, it assumes no liquidation value for the inventory, no growth rate or capital expenditures. Also the use of EBITDA as a proxy for profits and COGS as a proxy for production costs could affect the estimate. It is also not possible to evaluate the estimate too rigorously because the transaction period range (60-100 days) is not estimated from the model. Given all this considerations, I believe that the estimation results in a plausable quantitative estimate of the parameter in the model.

\subsection{Robustness Checks}

The results may depend on the specific time period used in the study. First, it is possible that firms in the consumer discretionary sector were more sensitive to the negative business conditions that occurred in the second half of 2007 relative to firms in other sectors. It could result that firms with low measures of the absolute position have less profits for that period and less accounts receivable because of the slow down in sales relative to the firms with high measures of position. It is also possible that firms in consumer discretionary sector have less accounts receivable because they sell to retail consumers. I exclude firms with absolute measure of 0 in the robustness test regression presented in Table 7 specifications (1) and (2). The positive relationship between the measures of total normalized incentives and the measures of absolute position holds in the subsample of firms that excludes firms in the consumer discretionary sector.

To ensure that the results are not driven by the proxy for profitability used, I also use EBIT and Net Income (NI) as two alternative proxies for profits in the estimation of $\mathrm{Eq}(6)$. The estimates of $\beta$ regressions are positive and statistically significant as predicted by the model (Table 7 specifications (3)-(6)).

\subsection{Alternatives}

In this paper I focus on the test of the Kim and Shin (2011) because their model provides empirical predictions about the position of the firm in the supply chain and

\footnotetext{
${ }^{29}\left(1+r_{t}\right)^{365 / t}$ where $t$ is the number of days. The standard error of the annual estimate is $8-15 \%$.
} 
its use of trade credit. These predictions are unique to their model and therefore allow a powerful test that can reconcile the patterns of trade credit that can't be explained by other models. Even though there are no models that I am aware of that make explicit predictions about the vertical position, there are models that provide an alternative explanation to the positive relationship between accounts receivable and accounts payable. In this section I try to test this alternative explanation.

The alternative explanation for the positive relationship is provided by Banerjee, Dasgupta, and Kim (2004) and Fabbri and Klapper (2008). According to their argument, firms might try to match maturities of assets and liabilities for risk management purposes. Therefore the positive relationships between receivables and payables is explained by the fact that they have similar maturities. I address this alternative in a cross-sectional analysis.

The empirical results of the cross-sectional analysis is presented in Table6. In specification (1) the left hand side variable is accounts receivable divided by total revenues and the right hand side variables include the log of total assets and age, profitability, measures of inventory levels, leverage, undrawn revolving credit divided by total assets, indicator variables for incorporation in US, whether the firm is independent or a subsidiary, whether it is publicly traded, industry dummies 30 and an intercept. Only the public status indicator variable, which is assigned a value of 1 when the company is traded, has a positive and statistically significant coefficient in this specification. This result suggests that firms that are publicly traded have a better access to capital and extend more trade credit to their customers.

Specification (2) includes accounts payable divided by total revenues as an additional explanatory variable. The coefficient on this variable is positive, statistically and economically significant. One standard deviation change in the normalized accounts payable increases the level of normalized receivables by $5.5 \%\left(0.409^{*} 0.135\right)$.

To test the maturity matching hypothesis I use the fact that revolving credit lines have similar maturity to accounts payables and therefore should play a similar role in the determination of accounts receivable. I include revolving credit divided by total assets as an explanatory variable in specification (3) of Table 6. The coefficient on revolving credit divided by total assets in this regression is positive and statistically sig-

\footnotetext{
${ }^{30}$ The industry dummies are defined at the six digits GICS level (22 industries).
} 
nificant at the $10 \%$ significant level. However, the coefficient is one order of magnitute smaller than the coefficient for payables in specification (2). One standard deviation change in revolving credit divided by total assets ratio increases receivables divided by total revenues by $0.56 \%\left(0.048^{*} 0.116\right)$. Specification (4) includes both payables and revolving credit line as explanatory variables. In this specification, the coefficient on payables is statistically and economically significant while the coefficient on revolving credit is marginally significant and economically insignificant.

The positive relationship between accounts receivable and accounts payable can be consistent with the maturity matching explanation if payables are preferred over revolving credit lines as a source of short-term finance. However, this hypothesis does not explain why would revolving credit be a more expensive source of finance relative to the trade credit and why would firms use the trade credit and revolving credit simultaneously. The implied interest rate on the trade credit contracts can be very high. For example, a contract that provides $2 \%$ early payament if the firm pays after 10 days instead of 30 days, has an implied annual interest rate of more than $40 \%$. Ng, Smith, and Smith (1999) using a survey data of vendors document the large proportion of firms that forego early payment discount: $38.6 \%$ occasionaly, $22.8 \%$ half of the time, $27.9 \%$ frequently. It is hard to believe that banks charge interest rate higher than $40 \%$ on the revolving credit. The moral hazard explanation of trade credit proposed by Kim and Shin (2011) suggests that firms would prefer to forego the discount in order to provide the right incentives to their suppliers. Moreover, the survey data of vendors suggests that OEM 31 are less likely to pay cash for the inputs and are less likely to be offered a trade credit contract with the early repayment discount option. It suggests that suppliers are not attempting to get early repayment that can decrease their incentives to exert effort. Overall, the cross-sectional results provide an additional evidence for the moral hazard explanation of trade credit.

\section{Conclusion}

In this paper I test the theoretical model of Kim and Shin (2011) that relates two seemingly unrelated questions: why firms use trade credit and how firms get incentives in long production chains. They argue that trade credit is used as an incentive device to make production chains feasible. To test this theory one needs to observe not only

\footnotetext{
${ }^{31}$ Buyers who use the product as an intermediary input.
} 
direct relationships between suppliers and customers but to construct the entire structure of the production chains. I use a novel database to identify supplier-customer relationships and develop a methodology to measure vertical and relative position for a large sample of firms. I use the measures of position to estimate two structural equations derived from the optimal contract solution proposed by the theoretical model.

I document several results that support the model. First, there is a positive relationship between the vertical position of the firm and the measures of incentives that it has. Second, there is a positive relationship between the relative position of a pair of firms in the supply chain and the difference in their incentives. Third, I use the pair-wise regression to test for the intercept which according to the structural equation should be indistinguishable from zero. The estimation results don't allow me to reject the model based on this test. Lastly, the estimated parameter of the model results in a pleasurable range what is an evidence in favor of the model.

The results reported in this paper invite additional investigation of the relationship between trade credit and industrial structure. First, the theoretical model assumes that supply chains are perfectly vertical while the empirical analysis reveals that supply chains are highly interconnected and firms have more than one supplier or one customer. Even though the fundamental moral hazard problem still exists, it is interesting to analyze how a number of customers can affect the incentives. For example, customers may be subject to a free raider problem where each one relies that other will provide the incentives. Another implication can be regarding the redeployment value of inventory. The model assumes that if the chain is liquidated the inventory of intermediary goods is worthless because they are highly specialized for the customer. However, when there is a number of customers then supplier can sell the output to another customer. This resale opportunity decreases supplier's cost of shirking and as a result requires more incentives. The resale motif would suggest a positive relationship between the number of customers and the level of incentives.

The theoretical model can also be extended to account for competition in the product market. The cost of shirking can be higher when a customer can switch to another supplier. However, even if the firm switches to another supplier it still would need to provide incentives to the new supplier who is also subject to the moral hazard considerations. Therefore, it is not clear that switching suppliers is a credible threat, especially when the ability of the initial supplier to supply high quality goods is not questionable. 
The extension of the model to account for asymmetric information about the ability of the supplier is also interesting. The intuition says that older firms should have a reputation premium because their age signals that they survived longer. However, the fact that firms at the top of the production chains are less likely to be affected by liquidation of the final good producers suggests that firm's age should be a less informative indicator of ability for firms at higher position. Extension of the model to include asymmetric information can introduce interesting empirical implications how incentives are related to the age of the firm and to a cross product of age with vertical position.

Lastly, the model does not discuss the option of vertical integration. The use of profits and trade credit achieves the first best effort by firms in the supply chain and therefore vertical integration is not going to introduce any improvements. However, the model would imply that vertical integration is necessary whenever the moral hazard problems are so severe that trade credit and profits can not solve the problem or when firms can't make the initial investment in working capital. Also while the benefits of vertical integration are clear in this framework, the costs are not explicit. It can be a result of the assumption that firms are organized in a perfectly vertical supply chain. The empirical analysis conducted in this paper reveals a complex structure of the supply chains. For example, one firm may sell inputs to two customers that compete with each other. If one of the customers vertically integrates with its supplier to eliminate moral hazard concerns, then it can affect the willingness of its competitor to continue the supplier-customer relationship with the integrated firm. This type of strategic behavior can introduce costs of vertical integration. The industrial structure of production constructed in this paper can be important element in empirical analysis of this type of costs.

\section{References}

BanerJee, S., S. Dasgupta, and Y. Kim (2004): "Buyer-Supplier Relationships and Trade Credit," Working paper.

Biais, B., And C. Gollier (1997): "Trade credit and credit rationing," Review of Financial Studies, 10(4), 903-937. 
Boissay, F. (2006): "Credit Chains and The Propagation of Financial Distress," Working paper series No. 573, European Central Bank.

Burkart, M., and T. Ellingsen (2004): "In-Kind Finance: A Theory of Trade Credit," The American Economic Review, 94(3), 569-590.

Burkart, M., T. Ellingsen, and M. Giannetti (2006): "What You Sell is What You Lend? Explaining Trade Credit Contracts," Review of Financial Studies, Forthcoming.

Codse, R. (1937): "The Nature of the Firm," Economica, 4(16), 386-405. (1992): "The Institutional Structure of Production," The American Economic Review, pp. 713-719.

Cuñat, V. (2007): "Trade Credit: Suppliers as Debt Collectors and Insurance Providers," Review of Financial Studies, 20(2), 491.

Fabbri, D., and L. F. Klapper (2008): "Trade Credit Supply, Market Power and the Matching of Trade Credit Terms," Working paper.

Frank, M., and V. Maksimovic (1998): "Trade Credit, Collateral, and Adverse Selection," Unpublished manuscript, University of Maryland.

Kim, S., And H. S. Shin (2011): "Sustaining Production Chains Through Financial Linkages," Princeton University Working Paper.

KiYotaki, N., and J. Moore (1997): "Credit Chains," mimeo.

NG, C., J. Smith, and R. Smith (1999): "Evidence on the Determinants of Credit Terms Used in Interfirm Trade," The Journal of Finance, 54(3), 1109-1129.

Petersen, M., and R. Rajan (1997): "Trade credit: theories and evidence," Review of Financial Studies, 10(3), 661-691.

RAJAN, R., And L. Zingales (1995): "What do we know about capital structure? Some evidence from international data," Journal of Finance, 50(5), 1421-1460.

Santos, J., and S. Longhofer (2003): "The Paradox of Priority," Financial Management, 32(1), 69-81.

Sufi, A. (2008): "Bank Lines of Credit in Corporate Finance: An Empirical Analysis," Forthcoming Review of Financial Studies. 
Table 1: Summary Statistics for the Whole Sample

\begin{tabular}{lcccccc}
\hline Variable & Mean & Median & Min & Max & Std. dev. & Obs. \\
\hline \hline & & & & & & \\
Total Assets (\$mm) [TA] & 2,313 & 191 & 0.0005 & 279,264 & 12,063 & 2,430 \\
Total Revenue (\$mm) [TR] & 2,240 & 160 & 0.0002 & 361,706 & 13,337 & 2,394 \\
Num Employees & 4,925 & 563 & 1 & 386,558 & 16,946 & 2,142 \\
Age & 36.7 & 24 & 1 & 234 & 35.7 & 2,461 \\
Receivables / TA & $15.5 \%$ & $12.9 \%$ & $0.1 \%$ & $61.4 \%$ & $12.7 \%$ & 2,372 \\
Payables / TA & $10.9 \%$ & $7.7 \%$ & $0.3 \%$ & $64.9 \%$ & $11.0 \%$ & 2,382 \\
Receivables / TR & $16.5 \%$ & $14.9 \%$ & $0.6 \%$ & $64.3 \%$ & $10.3 \%$ & 2,332 \\
Payables / TR & $12.6 \%$ & $8.4 \%$ & $0.7 \%$ & $79.7 \%$ & $13.5 \%$ & 2,252 \\
Net Rec / TA & $4.6 \%$ & $4.3 \%$ & $-46.1 \%$ & $40.4 \%$ & $12.1 \%$ & 2,337 \\
Total Debt /TA & $23.1 \%$ & $18.4 \%$ & $0.0 \%$ & $87.0 \%$ & $22.4 \%$ & 2,291 \\
Bank Debt / TA & $15.7 \%$ & $10.1 \%$ & $0.0 \%$ & $78.1 \%$ & $17.0 \%$ & 1,527 \\
ST. Debt / TA & $10.7 \%$ & $3.5 \%$ & $0.0 \%$ & $83.8 \%$ & $16.9 \%$ & 865 \\
Revolving Credit / TA & $9.3 \%$ & $5.0 \%$ & $0.0 \%$ & $53.9 \%$ & $11.6 \%$ & 1,164 \\
Und. Rev. Cred. / TA & $14.5 \%$ & $10.7 \%$ & $0.0 \%$ & $129.4 \%$ & $17.1 \%$ & 1,456 \\
EBITDA / TR & $9.1 \%$ & $10.0 \%$ & $-81.0 \%$ & $74.7 \%$ & $24.3 \%$ & 2,089 \\
EBIT / TR & $3.0 \%$ & $6.2 \%$ & $-82.7 \%$ & $54.9 \%$ & $22.2 \%$ & 2,078 \\
Net Income / TR & $-0.5 \%$ & $3.3 \%$ & $-88.2 \%$ & $53.8 \%$ & $22.3 \%$ & 2,047 \\
\hline
\end{tabular}

This table presents summary statistics for the whole sample of firms. Financial data is for Fiscal Year 2007. Age of companies is defined as a difference between 2008 and year of foundation. 'TR' stands for Total Revenue. 'TA' stands for Total Assets. 'Und. Rev. Cred.' is Undrawn Revolving Credit. EBIT is earnings before interest and taxes. EBITDA is earnings before interest, taxes, amortization and depreciation. Source of the data: Capital IQ. 
Table 2: Trade Credit Summary

\begin{tabular}{|c|c|c|c|c|c|c|}
\hline & $\begin{array}{c}\text { Mean } \\
\operatorname{Rec} / \mathrm{TA}\end{array}$ & $\begin{array}{c}\text { Median } \\
\text { Rec / TA }\end{array}$ & Obs. & $\begin{array}{c}\text { Mean } \\
\text { Pay / TA } \\
\end{array}$ & $\begin{array}{c}\text { Median } \\
\text { Pay / TA }\end{array}$ & Obs. \\
\hline \multicolumn{7}{|l|}{ Company Type: } \\
\hline Private & 0.155 & 0.120 & 273 & 0.095 & 0.074 & 272 \\
\hline Public & 0.155 & 0.130 & 2,099 & 0.111 & 0.078 & 2,110 \\
\hline \multicolumn{7}{|l|}{ Public Debt Dummy } \\
\hline No Public Debt & 0.184 & 0.163 & 285 & 0.115 & 0.084 & 284 \\
\hline Public Debt & 0.162 & 0.141 & 1,213 & 0.117 & 0.088 & 1,207 \\
\hline \multicolumn{7}{|c|}{1 if Undrawn Revolving Credit to TA $<=$ median (10.7\%), 0 otherwise } \\
\hline 0 & 0.178 & 0.163 & 706 & 0.103 & 0.083 & 706 \\
\hline 1 & 0.157 & 0.134 & 725 & 0.100 & 0.077 & 726 \\
\hline \multicolumn{7}{|l|}{ Headquarters: } \\
\hline Non-US & 0.178 & 0.154 & 113 & 0.120 & 0.097 & 113 \\
\hline US & 0.154 & 0.128 & 2,259 & 0.109 & 0.076 & 2,269 \\
\hline \multicolumn{7}{|l|}{ Company Status: } \\
\hline Subsidiery & 0.150 & 0.120 & 201 & 0.095 & 0.072 & 204 \\
\hline Independent & 0.155 & 0.130 & 2,171 & 0.111 & 0.077 & 2,178 \\
\hline \multicolumn{7}{|l|}{ Num. Employees } \\
\hline less or equal 500 & 0.144 & 0.102 & 998 & 0.121 & 0.078 & 1,002 \\
\hline more than 500 & 0.166 & 0.148 & 1,101 & 0.096 & 0.076 & 1,105 \\
\hline \multicolumn{7}{|c|}{1 if Total Assets above median (191 $\$ \mathrm{~mm}), 0$ otherwise } \\
\hline 0 & 0.163 & 0.129 & 1,161 & 0.129 & 0.087 & 1,168 \\
\hline 1 & 0.147 & 0.130 & 1,211 & 0.090 & 0.071 & 1,214 \\
\hline \multicolumn{7}{|l|}{ Primary Sector } \\
\hline Consumer Discretionary & 0.171 & 0.164 & 351 & 0.123 & 0.095 & 351 \\
\hline Energy & 0.092 & 0.054 & 485 & 0.086 & 0.053 & 495 \\
\hline Industrials & 0.198 & 0.179 & 486 & 0.123 & 0.095 & 485 \\
\hline Information Technology & 0.169 & 0.139 & 707 & 0.111 & 0.069 & 700 \\
\hline Materials & 0.134 & 0.127 & 343 & 0.105 & 0.082 & 351 \\
\hline Whole Sample & 0.155 & 0.129 & 2,372 & 0.109 & 0.077 & 2,382 \\
\hline
\end{tabular}

This table presents average and median levels of accounts receivable and accounts payable to total assets ('Rec / TA' and 'Pay / TA' respectively) for different subsamples and for the whole sample. Source: Capital IQ, Fiscal Year 2007. 
Table 3: Estimation of Eq.(6)

\begin{tabular}{lcccccc}
\hline \hline \multicolumn{7}{c}{$\log \left(\frac{\text { NetRec }_{j}+E B I T D A_{j}}{C O G S_{j}}\right)=\alpha+\beta$ Position $_{j}+\epsilon_{j}$} \\
& $(1)$ & $(2)$ & $(3)$ & $(4)$ & $(5)$ & $(6)$ \\
\hline \hline \multicolumn{7}{c}{} \\
Minimum Distance Measure of Absolute Position \\
beta & 0.247 & 0.328 & 0.111 & 0.202 & 0.302 & 0.379 \\
t-stat & 7.42 & 6.76 & 3.39 & 5.70 & 7.24 & 7.02 \\
alpha & -1.74 & -3.47 & -2.40 & -4.27 & -2.26 & -3.96 \\
t-stat & -25.46 & -49.09 & -34.48 & -55.20 & -30.15 & -55.93 \\
Observations & 748 & 703 & 719 & 685 & 717 & 672 \\
$R^{2}$ & 0.110 & 0.168 & 0.021 & 0.066 & 0.142 & 0.182 \\
\multicolumn{7}{c}{} \\
Median Distance Measure of Absolute Position & \\
beta & 0.132 & 0.182 & 0.060 & 0.102 & 0.170 & 0.217 \\
t-stat & 7.01 & 6.66 & 2.98 & 4.87 & 7.69 & 7.11 \\
alpha & -1.85 & -3.65 & -2.46 & -4.34 & -2.44 & -4.20 \\
t-stat & -18.97 & -33.48 & -24.57 & -40.98 & -24.63 & -39.94 \\
Observations & 748 & 703 & 719 & 685 & 717 & 672 \\
$R^{2}$ & 0.093 & 0.154 & 0.018 & 0.051 & 0.132 & 0.178 \\
\hline
\end{tabular}

This table presents estimation with OLS of six specifications:

(1): $\log \left(\frac{\operatorname{NetRec}_{j}+E B I T D A_{j}}{C O G S_{j}}\right)=\alpha+\beta$ Position $_{j}+\epsilon_{j}$

(2): $\log \left(\frac{\text { NetRec }_{j}+E B I T D A_{j}}{N u m \cdot E m p \cdot j}\right)=\alpha+\beta$ Position $_{j}+\epsilon_{j}$

(3): $\log \left(\frac{\text { NetRec }_{j}}{\text { COGS }_{j}}\right)=\alpha+\beta$ Position $_{j}+\epsilon_{j}$

(4): $\log \left(\frac{\text { NetRec }_{j}}{\text { Num.Emp.j }}\right)=\alpha+\beta$ Position $_{j}+\epsilon_{j}$

(5): $\log \left(\frac{E B I T D A_{j}}{\operatorname{COGS}_{j}}\right)=\alpha+\beta$ Position $_{j}+\epsilon_{j}$

(6): $\log \left(\frac{E B I T D A_{j}}{\text { Num.Emp.j }}\right)=\alpha+\beta$ Position $_{j}+\epsilon_{j}$

Standard errors are White-corrected for heteroscedasticity and residuals are assumed to be non-independent for any two firms that are involved in supplier-customer relationship. 'NetRec' is accounts receivable minus accounts payable, EBITDA is earnings before interest, taxes, depreciation and amortization, COGS is cost of goods sold, Num. Emp. is number of employees, Position measure is calculated according to minimum or median measures of the absolute position defined in Section 4.1. 
Table 4: Estimation of Eq.(7): Pair-wise Regression

\begin{tabular}{llll}
\hline \multicolumn{4}{c}{$D_{k}=\alpha+\beta$ Relative Position } \\
& $(1)$ & $(2)$ & $(3)$ \\
\hline beta & $0.041^{* *}$ & $0.056^{* * *}$ & $0.049^{* * *}$ \\
t-stat & 2.158 & 3.135 & 2.43 \\
alpha & 0.043 & 0.056 & 0.165 \\
t-stat & 0.377 & 0.455 & 1.105 \\
Observations & 190,493 & 144,349 & 112,885 \\
$R^{2}$ & 0.004 & 0.008 & 0.006 \\
\hline$* * * \mathrm{p}<0.01, * *$ & $\mathrm{p}<0.05, * \mathrm{p}<0.1$ &
\end{tabular}

This table presents estimation of equation (7) using OLS. The left hand side variable is log of net receivables (accounts receivable minus accounts payable) plus earnings before interest, taxes, depreciation and amortization (EBITDA) to cost of goods sold (COGS) of firm $i+j$ minus the same variable for firm $i$. The right hand side variable is $j$ which is the relative position between the two firms. If firm $a$ supplies to firm $b$ then the relative position between them is 1 . If firm $a$ supplies to firm $b$ and firm $b$ supplies to firm $c$ then the relative position between firm $a$ and the firm $c$ is 2 . Specification (1) is for all pairs of firms that belong to the same production chain. Specification (2) eliminates possible "loop": if both $A$ is a supplier to $B$ and $B$ is a supplier to $A$ then I use this pair of firms only once where I assume that the shortest distance between the two firms is the relevant production chain and the reverse relationship is noise (I exclude pairs if the distance from $A$ to $B$ is the same as from $B$ to $A$.) Specification (3) excludes all observations with "loops": $A$ is a direct or indirect supplier to $B$, but $B$ is not direct or indirect supplier to $A$. Standard errors are White-corrected for heteroskedasticity. Residuals are assumed to be non-independent between two observations that share the same firm. Specifically, when one observation is difference between firms $a$ and $b$ and another observation is a difference between firms $a$ and $c$ or $b$ and $c$ then these two observations share firm $a$ or firm $b$ and therefore are assumed to be non-independent. 
Table 5: Firm-level Regression with Controls

$$
\text { Dependent Variable: } \quad \log \left(\frac{\operatorname{NetRec} c_{i}+E B I T D A_{i}}{C O G S_{i}}\right)
$$

$(1)$

\begin{tabular}{|c|c|c|c|c|}
\hline & (1) & (2) & (3) & (4) \\
\hline Minimum Measure of Position & $\begin{array}{c}0.127^{* *} \\
(0.052)\end{array}$ & $\begin{array}{c}0.136^{* * *} \\
(0.038)\end{array}$ & $\begin{array}{l}0.079^{*} \\
(0.039)\end{array}$ & $\begin{array}{l}0.015 \\
(0.070)\end{array}$ \\
\hline Inventory / Total Assets[TA] & $\begin{array}{c}-3.002^{* * *} \\
(0.721)\end{array}$ & & $\begin{array}{l}-1.190 \\
(0.700)\end{array}$ & $\begin{array}{l}-1.129 \\
(0.779)\end{array}$ \\
\hline Sales / TA & & $\begin{array}{c}-0.862^{* * *} \\
(0.114)\end{array}$ & $\begin{array}{c}-0.772^{* * *} \\
(0.166)\end{array}$ & $\begin{array}{c}-0.764^{* * *} \\
(0.199)\end{array}$ \\
\hline $\log ($ Competitors +1$)$ & & $\begin{array}{c}-0.131^{* * *} \\
(0.039)\end{array}$ & $\begin{array}{c}-0.105^{* *} \\
(0.047)\end{array}$ & $\begin{array}{c}-0.096^{*} \\
(0.050)\end{array}$ \\
\hline $\log ($ Customers +1$)$ & & & $\begin{array}{l}-0.069 \\
(0.066)\end{array}$ & $\begin{array}{l}-0.054 \\
(0.053)\end{array}$ \\
\hline Log(Suppliers +1) & & & $\begin{array}{l}-0.044 \\
(0.063)\end{array}$ & $\begin{array}{l}0.002 \\
(0.062)\end{array}$ \\
\hline Log(Total Assets) & & & $\begin{array}{l}0.031 \\
(0.039)\end{array}$ & $\begin{array}{l}0.018 \\
(0.044)\end{array}$ \\
\hline Total Debt / TA & & & $\begin{array}{c}-0.824^{* * *} \\
(0.126)\end{array}$ & $\begin{array}{c}-0.859^{* * *} \\
(0.165)\end{array}$ \\
\hline Constant & $\begin{array}{c}-1.173^{* * *} \\
(0.146)\end{array}$ & $\begin{array}{l}-0.297 \\
(0.203)\end{array}$ & $\begin{array}{l}-0.163 \\
(0.287)\end{array}$ & $\begin{array}{l}-0.235 \\
(0.275)\end{array}$ \\
\hline $\begin{array}{l}\text { Industry Dummies } \\
\text { Observations }\end{array}$ & No & No & No & $\begin{array}{l}\text { Yes } \\
684\end{array}$ \\
\hline $\begin{array}{l}\text { Observations } \\
\text { Adjusted } R^{2}\end{array}$ & $\begin{array}{c}689 \\
0.162\end{array}$ & $\begin{array}{c}748 \\
0.313\end{array}$ & $\begin{array}{c}684 \\
0.325\end{array}$ & $\begin{array}{c}684 \\
0.348\end{array}$ \\
\hline
\end{tabular}

The coefficients are estimated using ordinary least squares. Standard errors are White-corrected for heteroscedasticity and clustered at the industry level (22 clusters). All financial ratios in the regressions were winsorized at $1 \%$ and $99 \%$ levels. Financial data is for Fiscal Year 2007. Data source: Capital IQ. 
Table 6: Joint Determination of Receivables and Payables

\begin{tabular}{|c|c|c|c|c|}
\hline \multirow[b]{2}{*}{ VARIABLES } & \multicolumn{4}{|c|}{ Receivables / Total Revenues } \\
\hline & (1) & (2) & (3) & (4) \\
\hline \multirow[t]{2}{*}{ Payables / Total Revenue } & & $0.409 * * *$ & & $0.369^{* * *}$ \\
\hline & & $(0.049)$ & & $(0.062)$ \\
\hline \multirow[t]{2}{*}{ Log TotalAssets (TA) } & -0.000 & -0.002 & -0.001 & -0.002 \\
\hline & $(0.001)$ & $(0.001)$ & $(0.001)$ & $(0.002)$ \\
\hline \multirow[t]{2}{*}{ Log_Age } & -0.001 & 0.001 & 0.002 & 0.003 \\
\hline & $(0.003)$ & $(0.003)$ & $(0.003)$ & $(0.003)$ \\
\hline \multirow[t]{2}{*}{ US_Dummy } & -0.027 & -0.014 & -0.019 & -0.004 \\
\hline & $(0.020)$ & $(0.019)$ & $(0.019)$ & $(0.018)$ \\
\hline \multirow[t]{2}{*}{ Operating_Dummy } & -0.008 & -0.009 & -0.012 & $-0.016^{* *}$ \\
\hline & $(0.008)$ & $(0.006)$ & $(0.009)$ & $(0.006)$ \\
\hline \multirow[t]{2}{*}{ Public_Dummy } & $0.019 * * *$ & $0.015^{* * *}$ & $0.020^{* * *}$ & $0.015^{* *}$ \\
\hline & $(0.004)$ & $(0.005)$ & $(0.006)$ & $(0.006)$ \\
\hline \multirow[t]{2}{*}{ EBITDA / Total Revenues } & 0.008 & $0.051^{* * *}$ & 0.028 & $0.065^{* * *}$ \\
\hline & $(0.015)$ & $(0.018)$ & $(0.016)$ & $(0.017)$ \\
\hline \multirow[t]{2}{*}{ Inventory / Total Revenues } & 0.016 & 0.025 & 0.013 & 0.021 \\
\hline & $(0.033)$ & $(0.029)$ & $(0.033)$ & $(0.031)$ \\
\hline \multirow[t]{2}{*}{ Total Debt / Total Assets } & -0.016 & -0.021 & -0.033 & $-0.035^{*}$ \\
\hline & $(0.017)$ & $(0.016)$ & $(0.019)$ & $(0.019)$ \\
\hline \multirow[t]{2}{*}{ Undrawn Revolving Credit / TA } & 0.001 & 0.013 & $-0.030 * *$ & -0.009 \\
\hline & $(0.015)$ & $(0.010)$ & $(0.014)$ & $(0.011)$ \\
\hline \multirow[t]{2}{*}{ Revolving Credit / TA } & & & $0.048^{*}$ & $0.045^{*}$ \\
\hline & & & $(0.025)$ & $(0.026)$ \\
\hline Industry Dummies & Yes & Yes & Yes & Yes \\
\hline Observations & 1162 & 1162 & 783 & 783 \\
\hline Adjusted $R^{2}$ & 0.185 & 0.308 & 0.215 & 0.322 \\
\hline
\end{tabular}

The dependent variable is accounts receivable to total revenues (TR). The coefficients are estimated using ordinary least squares. Each regression has a constant and industry dummies whose coefficients is not reported. Standard errors are White-corrected for heteroscedasticity and clustered at the industry level (22 clusters). All financial ratios in the regressions were winsorized at $1 \%$ and $99 \%$ levels. Financial data is for Fiscal Year 2007. Log_Age is a natural logarithm of firm's age defined as a difference between year 2008 
Table 7: Estimation of Equation (6): Robustness Tests

\begin{tabular}{|c|c|c|c|c|c|c|}
\hline VARIABLES & (1) & (2) & (3) & (4) & (5) & (6) \\
\hline \multirow[t]{2}{*}{ Minimum Measure } & $0.232^{* *}$ & & $0.212^{* * *}$ & & $0.206^{* * *}$ & \\
\hline & $(0.106)$ & & $(0.058)$ & & $(0.036)$ & \\
\hline \multirow[t]{2}{*}{ Median Measure } & & $0.142^{* * *}$ & & $0.114^{* * *}$ & & $0.108^{* * *}$ \\
\hline & & $(0.045)$ & & $(0.034)$ & & $(0.026)$ \\
\hline \multirow[t]{2}{*}{ Constant } & $-1.687^{* * *}$ & $-1.910^{* * *}$ & $-1.916^{* * *}$ & $-2.015^{* * *}$ & $-2.009^{* * *}$ & $-2.089 * * *$ \\
\hline & $(0.221)$ & $(0.202)$ & $(0.138)$ & $(0.162)$ & $(0.138)$ & $(0.162)$ \\
\hline Observations & 597 & 671 & 699 & 699 & 657 & 657 \\
\hline$R^{2}$ & 0.068 & 0.078 & 0.078 & 0.066 & 0.075 & 0.060 \\
\hline
\end{tabular}

$* * * \mathrm{p}<0.01,{ }^{* *} \mathrm{p}<0.05,{ }^{*} \mathrm{p}<0.1$

This table presents estimation of equation (6) using OLS. Each specification uses a different proxy for the absolute position of a firm in a supply chain. Standard errors are White-corrected for heteroskedasticity and clusters at the industry level. In specifications (1) and (2), the left hand side variable is $\log$ of net receivables plus EBITDA to COGS. Firms with measures of absolute position equal to 0 are excluded from the sample.

In specifications (3) and (4), the left hand side variable is log of net receivables plus EBIT to COGS. In specifications (5) and (6), the left hand side variable is log of net receivables plus Net Income to COGS. 


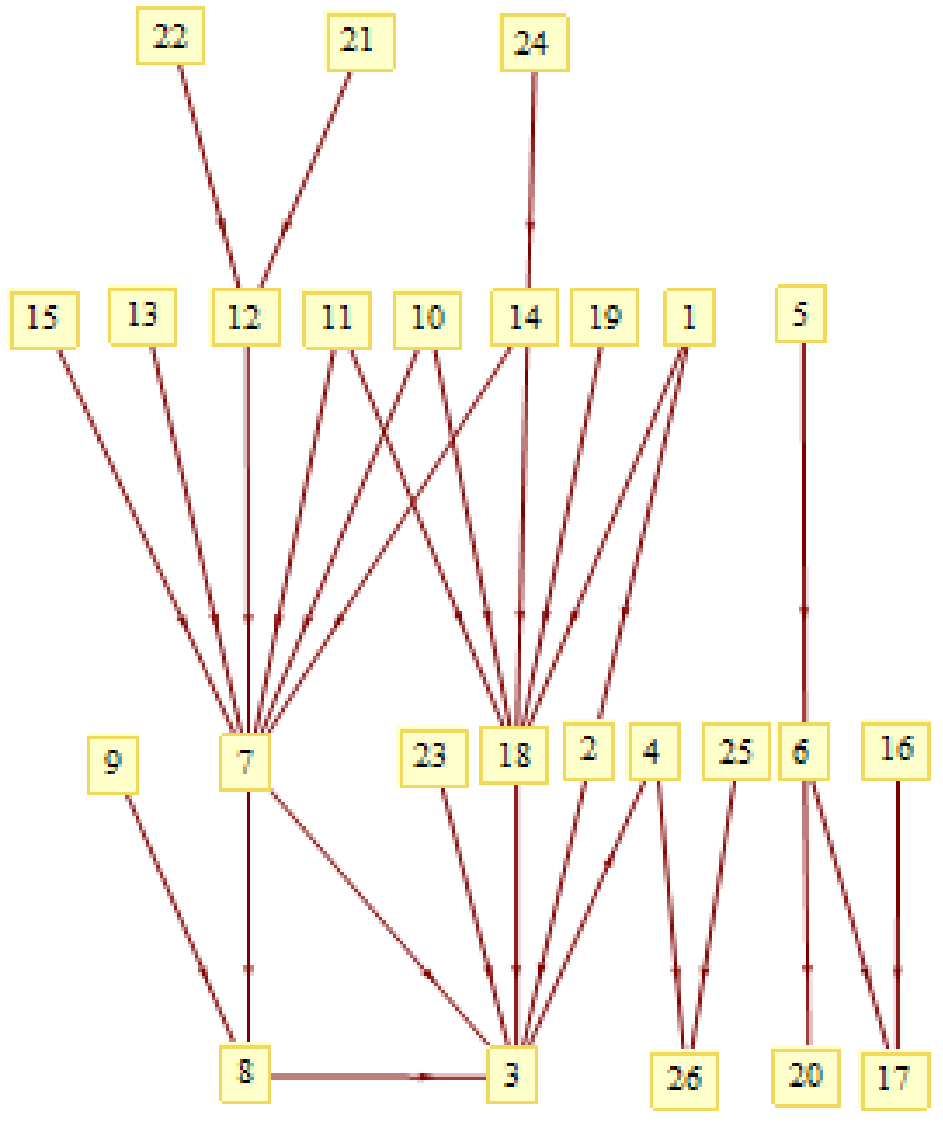

Figure 1: An Example of the Industrial Structure of Firms

The graph illustrates an example of the structure of supply chains composed of 26 firms. Firms at the bottom of the graph belong to the consumer electronics industry. Each firm appears as a node on the graph. Arrows start from the supplier and point to the customer. The vertical position of each firm is according to the minimum measure of absolute position. The horizontal position has no meaning. 


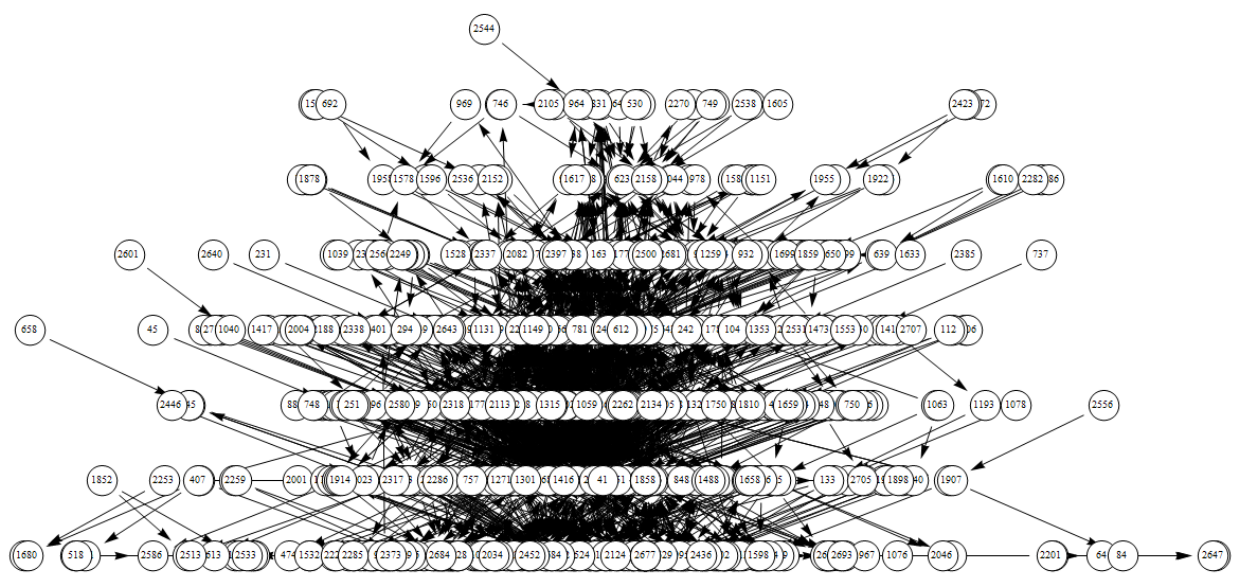

Figure 2: Industrial Structure of Firms in the Sample: Minimum Measure of Position

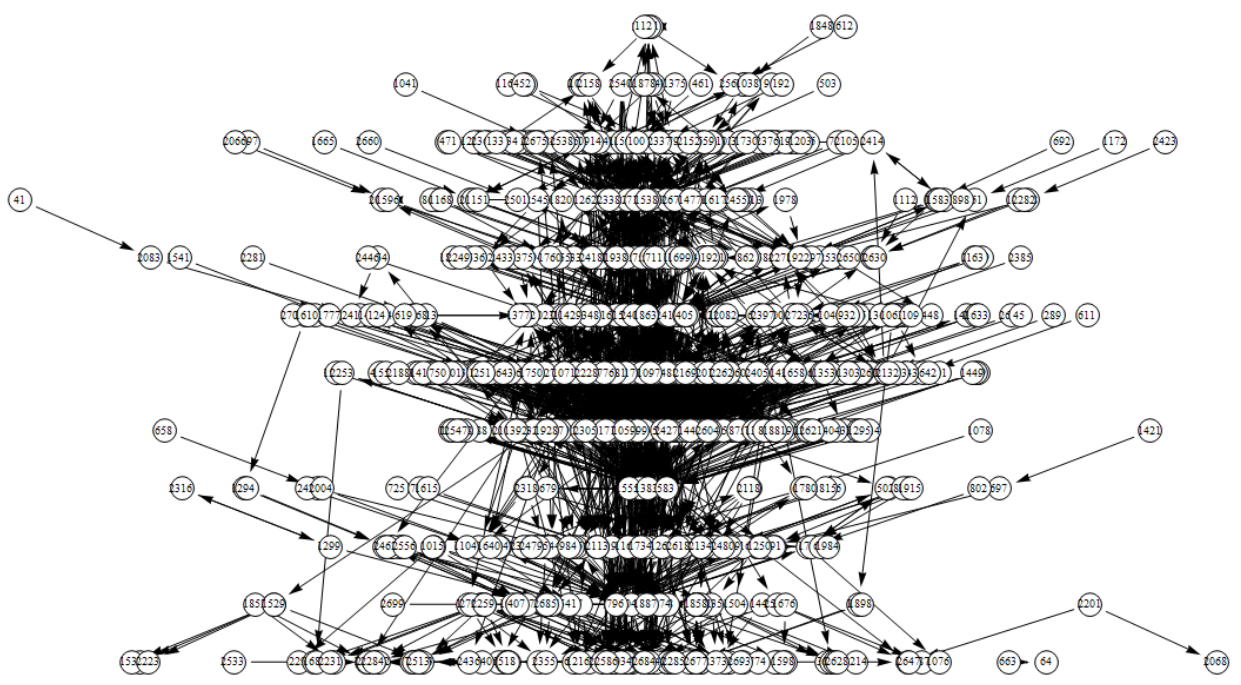

Figure 3: Industrial Structure of Firms in the Sample: Median Measure of Position

The graphs present the structure of supply chains composed of 990 firms. Each firm appears as a node on the graph. Arrows start from the supplier and point to the customer. The vertical position of each firm is according to the minimum measure of absolute position (top graph) or the median measure of absolute position (bottom graph) as defined in Section 4.1. The horizontal position has no meaning in these graphs. 


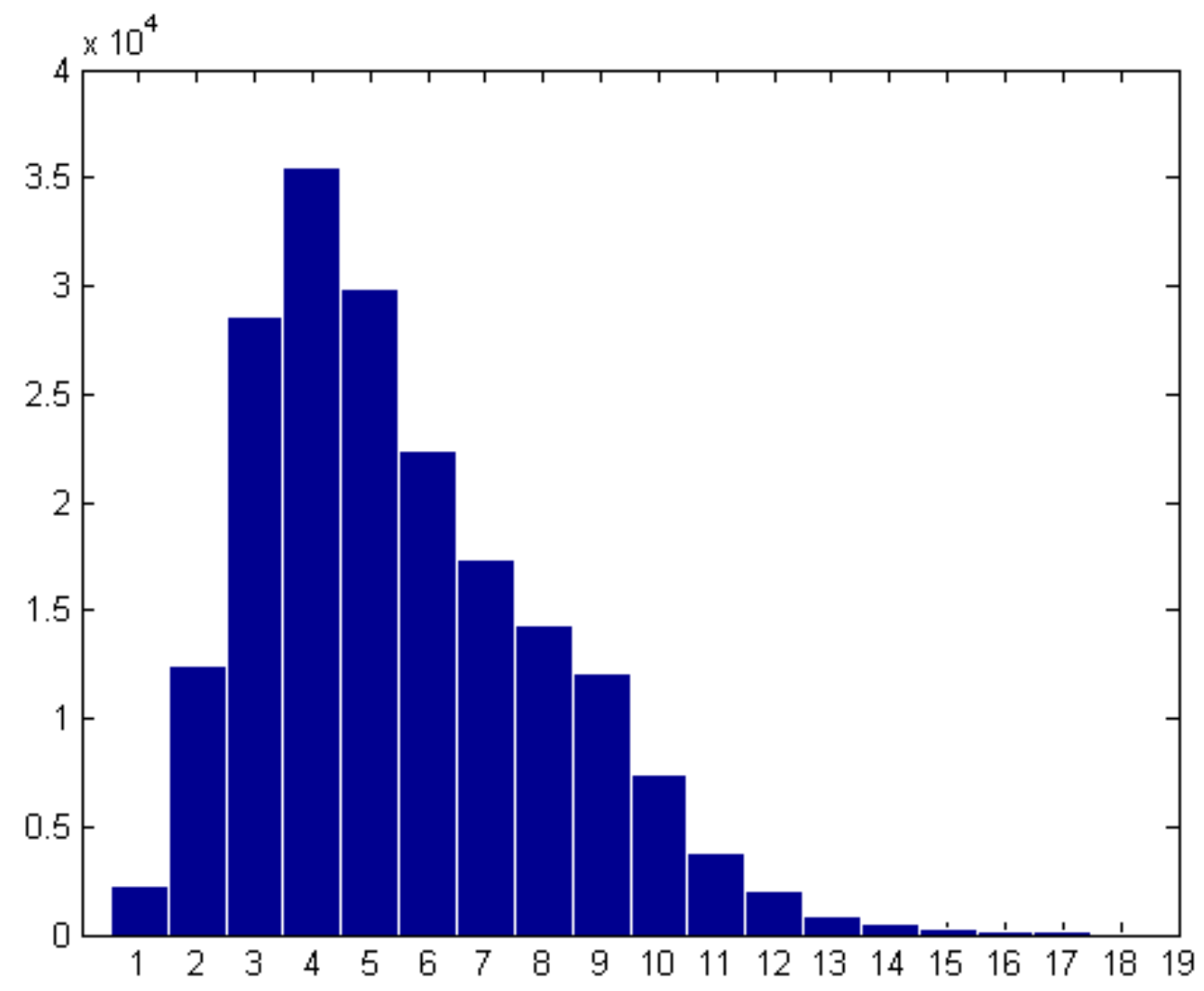

Figure 4: Histogram of the Relative Position Measure

The figure presents the histogram of the relative position measure defined for 190,493 pairs of firms. The definition of the measure appears in Section 4.1. The measure is used in the estimation of Eq(7) and the results of the estimation are reported in Table 4. 